\title{
The effect of disparity in visual cues on the goal gradient and the anticipatory gradient in the rat
}

ROBERT FRIED

RUTGERS UNIVERSITY ${ }^{1}$

Three groups of rats ran 16 acquisition trials, for water reward, in a multiple unit straight-alley maze. Group I was presented with a light stimulus in compartment I; group II in compartment III; and, group III in compartment V. The groups were divided in two and on the 17 th trial were presented with the stimulus in a different compartment. It was shown that locomotor patterns established during acquisition trials, conforming generally to those described by Hull, were affected by the change in the location of the light stimulus. The change in locomotor speed patterns suggests that goal and anticipatory gradients are essentially indeces of perception of cues to relative position in the maze.

According to Hull (1943), rats develop a positively accelerated speed of locomotion gradient in a straight runway. After a few trials, Ss manifest an anticipatory reaction in that they decelerate in the region near the goal.

It is proposed that acceleration gradients result from chained behavior sequences maintained by secondary reinforcement; and, that generalization has retroactive effects on maze locomotion (Bergum, 1960; Ehrenfreund, 1954; Hull, 1934; Saltzman, 1959).

It is the purpose of this study to show that the role of relevant maze stimuli in conditioning of locomotor behavior is to provide position cues and that the anticipatory gradient is, essentially, an index of the discrimination of these cues.

\section{Method}

Subjects. Sixty naive male white rats (SpragueDawley), approximately 85 days old.

Apparatus. Five identical adjoining plywood compartments $15 \times 9 \times 9$ in., flat black inside and out, with an opaque Plexiglas top.
Table 1. Compartment in which the light stimulus was presented during the 16 acquisition trials, and compartment in which it appeared of the test trial, e.g., trial 17.

$$
\text { Acquisition Test Trial }
$$

Light in Compartment Light in Compartment

\begin{tabular}{lcc}
\hline Group I & I & III \\
Group II & I & V \\
Group III & III & V \\
Group IV & III & I \\
Group V & V & III \\
Group VI & V & G. \\
\hline
\end{tabular}

A light stimulus could be presented, in each compartment, through an aperture $1 / 4$ in. diameter on the compartment right side. A baffle at the entrance to each compartment prevented $S$ from perceiving the light before entering it.

Compartment floors consisted of adjacent 3 in. wide treadles resting lightly on a microswitch: when depressed, they set in motion a programmer emitting 1/5 sec. pulses recorded on an Esterline-Angus recorder.

Procedure. All Ss were on $22 \mathrm{hr}$. water deprivation schedule.

They began trials in a start box and terminated in a goal box containing a dimly illuminated water spout where they were permitted to remain for 45 sec., after they traversed the five maze compartments. Each $\mathrm{S}$ underwent two trials per day.

Maze compartments were interchanged between trials, and water bottles were placed along the maze exterior to confound odor cues.

A two factor mixed-design (see Table 1) was employed. From pilot evidence, it was established that

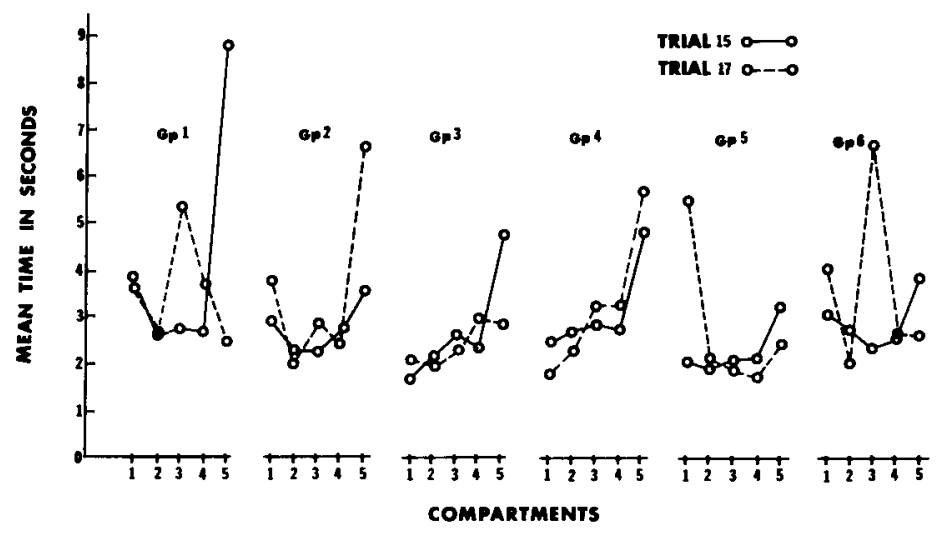

Fig. 1. Mean time, in seconds, spent by each group in each compartment of the maze on the 15th acquisition trial and on the test trial (trial 17) when the maze stimuli were systematically changed. 
12 trials are sufficient to stabilize locomotion patterns, but each $S$ underwent 16 acquisition trials with the light stimulus in one of the compartments, e.g., I, III, or $V$. On the 17th trial, the light stimulus was changed to another compartment. The comparisons in the analysis consist of measures of locomotor speed in the critical compartments on trial 15 and 17.

Results

Figure 1 summarizes mean time spent by each group in each compartment on trial 15 and 17. Analysis of variance indicates that there are no significant differences between the groups on trial $15(\alpha=.05)$, e.g., trend analysis indicates homogeneity of locomotorspeed slopes. However, on trial 17 there were significant differences in trend.

\section{Discussion}

In nearly all groups, locomotor-speed curves were obtained with slopes corresponding to the anticipatory and goal gradient described by Hull (1943). The method by which they were obtained suggests that artifacts such as those reported by Knarr \& Collier (1962), e.g., speed-bursts, were not involved since there is no reason to believe that genetically determined locomotor patterns would be systematically disturbed by manipulation of alley cues.

On the contrary, it may be concluded that locomotor speed-gradients represent orderly evocation of motor responses by maze stimuli with which the responses had been previously associated.

\section{References}

Bergum, B. O. Gradients of generalization in secondary reinforcement. J. exp. Psychol., 1960, 59, 47-53.

Ehrenfreund, D. Generalization of secondary reinforcement in discrimination learning. J. comp. physiol. Psychol., 1954, 47, 311314.

Hull, C. L. The rats speed of locomotion gradient in the approach to food. J. comp. Psychol., 1934, 17, 392-422.

Hul1, C. L. Principles of behavior. New York: D. Appleton Century Co., Inc. 1943. Pp. 95-145.

Knarr, F. A., \& Collier, G. Taste and consumatory activity in amount and gradient of reinforcement functions. J. exp. Psychol. $1962,63,579-588$.

Saltzman, I. J. Generalization of secondary reinforcement. J. exp. Psychol., 1950, 40, 189-193.

\section{Wote}

1. The writer is now at Hunter College of the City University of New York. 